\title{
Scholarly

\section{Comparison of Cytogenetic and Static Cytometry Procedures in the Evaluation of Potentially Malignant Oral Lesions}

\author{
L. Montebugnoli, ${ }^{1}$ I. Grelli, ${ }^{1}$ F. Cervellati, ${ }^{1}$ D. Servidio, ${ }^{1}$ C. Marchetti, ${ }^{1}$ \\ A. Farnedi, ${ }^{2}$ and M. P. Foschini' ${ }^{2}$ \\ ${ }^{1}$ Department of Oral Science, University of Bologna, 40125 Bologna, Italy \\ ${ }^{2}$ Department of Oncology and Haematology, Section of Anatomic Pathology, Bellaria Hospital University of Bologna, \\ 40139 Bologna, Italy
}

Correspondence should be addressed to L. Montebugnoli, lucio.montebugnoli@unibo.it

Received 9 June 2008; Accepted 10 November 2008

\begin{abstract}
Gross genomic damage or specific chromosomal alterations have been revealed by different laboratory procedures in potentially malignant oral lesions, but two or more procedures have never been applied at the same time to the same cell population. In the present study we considered cell suspensions obtained from 34 oral lesions at risk of malignancy to see whether they might harbour genetic alterations and whether a correlation exists between the results obtained by two different methods of assessing DNA aberrations. Each suspension underwent DNA-content assessment by static cytometry, and cytogenetic G-banding analysis of short-term primary cultures. DNA content was determined in a minimum of 1000 cells on a Fairfield ploidy analyser and results expressed as percent of aneuploid cells in the S-phase; cytogenetic analysis was carried out according to standard procedures on in situ G-banding metaphases, and results expressed as percent of metaphases with chromosomal alterations. The results showed that the percentage of metaphases with chromosomal alterations was significantly correlated with the percentage of aneuploid cells in the S-phase. In conclusion, genetic alterations can be revealed in the same oral specimen either by procedures studying DNA content in fixed cells or by procedures investigating chromosomal alterations in cultured and proliferating cells.
\end{abstract}

Copyright (C) 2008 L. Montebugnoli et al. This is an open access article distributed under the Creative Commons Attribution License, which permits unrestricted use, distribution, and reproduction in any medium, provided the original work is properly cited.

\section{Introduction}

It is widely accepted that an accumulation of genetic alterations underlies oral carcinogenesis [1-3], and that genetic alterations can be detected in oral lesions at risk of developing oral squamous cell carcinoma (OSCC) [4-9].

Different procedures have been successfully employed to disclose specific chromosomal alterations or gross genomic damage both in OSCC and in potentially malignant lesions [10-13]. Cytogenetic analysis has yielded a detailed picture of chromosomal changes, and is considered a powerful tool to detect heterogeneity in tumors. However, all these methods are labor intensive, and only mitotic cells are informative [14]. Ploidy analysis is a more straightforward procedure that has provided interesting information on gross genomic aberrations in OSCC and premalignant lesions [15-17]. Nonetheless, aneuploidy is considered to be only a generic indicator of genetic instability and diploidy does not exclude the possibility of karyotypic changes leading to minimal or no net loss or gain of genetic material.To date, few studies have analyzed the relationship between aneuploidy and chromosomal imbalance on solid tumors, in particular OSCC [18-22].

A statistical correlation between the DNA content by flow cytometry and the magnitude of the chromosomal aberration on OSCC has been reported, but, to the best of our knowledge, no studies have compared static cytometry and cytogenetic analysis on lesions defined by WHO as "precancerous conditions" such as oral lichen planus and squamous cell hyperplasia [23, 24].

The aim of this study was to establish whether potentially malignant oral lesions may harbor genetic instability, and above all whether a relationship exists between data obtained by two quite different methods of studying DNA alterations, that is, procedures determining DNA content in fixed cells or procedures investigating chromosomal alterations in cultured and proliferating cells. 


\section{Material and Methods}

Histology and cell suspensions were obtained from 34 consecutive patients referred to the Department of Oral Sciences, the University of Bologna, Bologna, Italy between January and July 2007.

Fresh biopsies from all subjects were divided into two specimens: one was formalin fixed for histological analysis, while the other underwent cell cultures for cytogenetic investigation and static cytometry.

2.1. Histology. Formalin-fixed tissues were paraffin embedded according to routine protocols.

Twenty six oral lesions were clinically and histologically diagnosed as "classic" oral lichen planus (OLP) and 8 as oral leukoplakia. Histological diagnoses were performed following the criteria published in the WHO manual [23, 24]. Accordingly, all cases showing clinical features of leukoplakia had histological features of squamous cell hyperplasia. Diagnosis of "classic" OLP was made when the lesion fulfilled all currently available clinical and histological criteria [25]. No samples presented dysplastic changes. The presence of dysplasia was considered a criterion of exclusion from the study.

2.2. Cell Cultures. Cell suspensions, obtained after enzymatic digestion with collagenase $(2000 \mathrm{U} / \mathrm{mL}$; GIBCO; Invitrogen Corporation, Auckland, New Zealand) at $37^{\circ} \mathrm{C}$ for $16-$ 18 hours, were seeded and cultured from 3 to 10 days in modified DMEM-F12 (GIBCO, Invitrogen Corporation, Auckland, New Zealand) supplemented with 10\% Foetal Bovine Serum (Hy-Clone Laboratories, Celbio, Milan, Italy) and antibiotics/Fungizone (GIBCO, Invitrogen Corporation, Auckland, New Zealand). Short-term cultures were processed to minimize fibroblast contamination [26], following the method currently applied for cultures on solid tumors [27, 28].

Each suspension underwent DNA-content assessment by static cytometry and G-banding chromosomal analysis of short-term cultures.

2.3. Cytogenetic Analysis. It was carried out according to standard procedures on in situ G-banding metaphases taken from primary short-term cultured cells. After culture and overnight incubation with Colcemid $(0.03 \mu \mathrm{g} / \mathrm{mL})$ (KaryoMAX Colcemid Solution, GIBCO, Invitrogen Corporation, Auckland, New Zealand), the cells were harvested using hypotonic treatment with $0.8 \%$ sodium citrate preheated to $37^{\circ} \mathrm{C}$ at room temperature for 35 minutes. The preparations were fixed four times with Carnoy's fixative, methanol, and glacial acetic acid (3:1). Chromosomes were G-banded using HCL and Wright stain. All G-banded metaphases were evaluated on three slides to exclude a clonal growth of the same cell. The number of appropriate (o valuable) metaphases ranged from 4 to 23 depending on the sample. The karyotypes were described according to the ISCN 1995 "an international system for human cytogenetic nomenclature” [29]. Karyotype was considered normal when $46, \mathrm{XX}$ or $46, \mathrm{XY}$ was observed; while altered karyotypes were diagnosed when chromosomal alterations were present. Alterations were diagnosed as clonal alterations (CAs) when gain of chromosome copies (trisomy) and structural alteration were present in a minimum of two metaphases, or when monosomy was present in a minimum of three metaphases. Nonclonal alterations (NCAs) comprised all other alterations, even if present in single copy. Results were expressed as percent of metaphases with chromosomal alterations (CA and NCA).

2.4. Static Cytometry. DNA content was determined in a minimum of 1000 cells on a Fairfield ploidy analyzer. Cell samples were stained with the Perceptronix's FeulgenThionin staining protocol (Clear2C-DNA Staining) and analyzed by the ClearCyte system (ClearCyte Inc., Vancouver, Canada). The system (fully automated image cytometer) scanned the slides and displayed images of cells with aneuploid DNA content on the computer monitor for visual review. The cytologist subsequently cleaned suspicious cell galleries of the remaining debris and reviewed diagnostic cells directly under the ClearCyte microscope. The European Society for Analytical Cellular Pathology (ESACP) task force on standardization of diagnostic DNA-image cytometry [30] has defined standards for the performance of these systems. Results were expressed as "percent of aneuploid cells in the S-phase" (cells not included in c2 and c4, with a DNA index comprised between 2.20 and 3.60).

For the statistical analysis, a multiple regression model was fitted to describe the relationship between the percent of aneuploid cells in S-phase by static cytometry and the percent of metaphases with chromosomal alterations by Gbanding analysis, independently or according to the type of oral lesions.

\section{Results}

Table 1 summarizes the results from cytogenetic analysis and DNA static cytometry.

3.1. Cytogenetic Analysis. Ten cases (6 from OLP and 4 from leukoplakias) did not show any altered metaphase; 2 cases (both from OLP) each one presented an altered composite clone in addition to the normal clone; 5 cases ( 4 from OLP and one from leukoplakias) presented altered clones and metaphases with NCA, and 17 cases (14 from OLP and 3 from leukoplakias) presented metaphases with only NCA in addition to the normal clone.

3.2. DNA Static Cytometry. The percentage of aneuploid cells in the S-phase ranged from $1 \%$ to $19 \%$ with a median of 4 (from $1 \%$ to $19 \%$ with a median of 7 in OLP samples and from $1 \%$ to $7 \%$ with a median of 4 in leukoplakias; $P=$ NS).

3.3. Correlation between Cytogenetic Analysis and Static Cytometry. The results of fitting a multiple regression model showed a significant relationship $(F=5.48 ; P<.03)$ between the percentage of aneuploid cells by static cytometry 


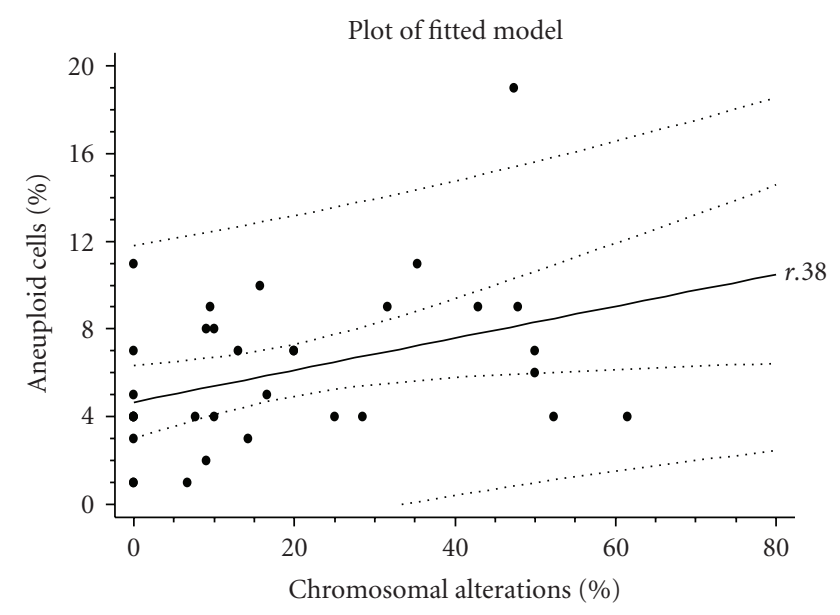

FIGURE 1: Relationship between the percentage of aneuploid cells in the S-phase and the percentage of metaphases with chromosomal alterations (CA and NCA).

and the percentage of metaphases with chromosomal alterations (CA and NCA) by cytogenetic analysis (Figure 1). The relationship was not influenced by the type of oral pathology.

\section{Discussion}

In recent years, chromosome banding analysis has given more insight into the genetic basis of tumorigenesis in OSCC [31-33]. Cytogenetic G-banding analysis of more than 200 short-term cultured OSCCs showed that most OSCCs display clonal chromosome aberrancies with multiple numeric and structural changes, underlying the high chromosomal instability of these tumors $[34,35]$. Chromosomal abnormalities were also demonstrated in OLP patients by the same technique [36].

Ploidy analysis, as a measure of gross genetic damage, has also provided information on DNA alterations in OSCC and in potentially malignant oral lesions and has been widely used as a more straightforward procedure [17, 37-39]. However, ploidy analysis has been criticized for its uncertainties on the populations of cells represented by diploid/peridiploid DNA histograms, and it has been demonstrated that diploidy does not exclude the possibility of karyotypic changes leading to minimal or no net loss or gain of genetic material. In addition, DNA cytometry cannot detect the aberrant clones when the fraction of nondiploid tumor cells is small.

Few studies have combined data from DNA cytometry and cytogenetic analysis on solid tumors, and little information is available on OSCC $[18,40]$. In 1999, EL Naggar reported a correlation between the DNA content evaluated by flow cytometry and the magnitude of the chromosomal aberration evaluated by fluorescence in situ hybridization (FISH) on 27 cases of OSCC [20]. The data were subsequently confirmed on 4 cases of OSCC by Hemmer and Prinz [22]. In 2000, Okafuji reported a positive relationship between ploidy and tumor size and the number of chromosomal alterations in 11 OSCCs [21]. In the same year, Hashimoto found that the number of chromosomal aberrations was higher in aneuploid tumors than in diploid lesions in 18 cases of OSCC [19].

No data on potentially malignant oral lesions have yet been published.

The results of our study, conducted on potentially malignant oral lesions, are inline with the result obtained on OSCC.

The strict relationship between aneuploidy and chromosomal imbalance is in fact underlined by the results from multiple linear regression showing that the percentage of aneuploid cells in S-phase was significantly related to the number of chromosomal alterations, both clonal and nonclonal, regardless of the type of oral lesion.

The S-phase fraction in a DNA histogram reflects the number of cells in an aneuploid status, and has been deemed to be representative of a lesion's proliferative activity and suggestive of its genetic stability [41]. S-phase measurement has been widely used in patients with different carcinomas [41-43] and is a clinically useful prognostic factor in patients with OSCC [43-48]. Additionally, the percentage of aneuploid cells in S-phase, unlike aneuploidy as a discrete biomarker, represents a continuous variable that allows the application of powerful statistical approaches like linear regression models to disclose a relationship with other continuous variables, such as the number of chromosomal alterations in the present study.

To the best of our knowledge, this is the first study that has applied this approach and has compared, at the same time, cytogenetic analysis and static cytometry on potentially malignant oral lesions [23, 24].

Our results confirm data from the literature showing that potentially malignant oral lesions may harbor many chromosomal anomalies [5, 36, 49]. However, it must be taken into account that the small number of the evaluated cases and the lack of any follow-up, doses not permit to state that the oral lesions with chromosomal anomalies associated with high numbers of aneuploid cells have an increased risk of developing cancer.

In fact, the relatively high percentage of structural and numerical karyotype alterations associated with a high percentage of aneuploid cells in OLP patients suggests that these abnormalities are not strictly related to the risk of cancerization, but probably to the consequence of repetitive processes of basal cell destruction and regeneration due to the autoimmune disease $[50,51]$. The real incidence of genetic imbalance in potentially malignant oral lesions and the relationship between chromosomal alterations and the risk of developing cancer were beyond the scope of this investigation. Longitudinal studies are in progress to evaluate the prognostic power of the parameters applied in the present study.

The results from the present study, besides confirming that potentially malignant oral lesions may be associated with a genetic instability, underline that the percentage of aneuploid cells, revealed by static cytometry, is closely related to the number of chromosomal alterations detected by cytogenetic G-banding analysis. The present study demonstrates that genetic alterations can be disclosed in the same oral 
TABLE 1: Cytogenetic data by G-banding, and percentage of aneuploid cells in the S-phase by static cytometry; CAs: clonal alterations; NCAs: nonclonal alterations.

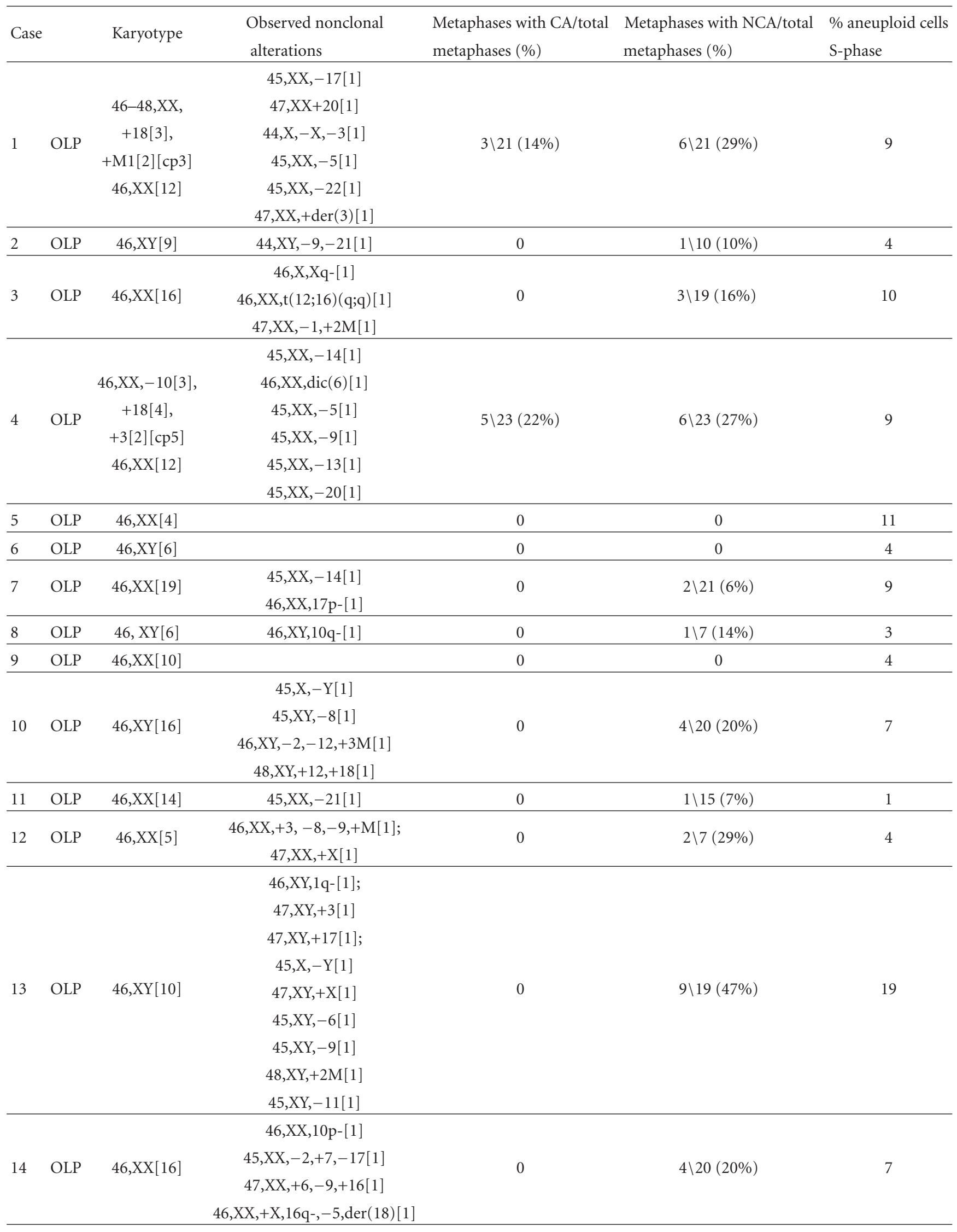


Table 1: Continued.

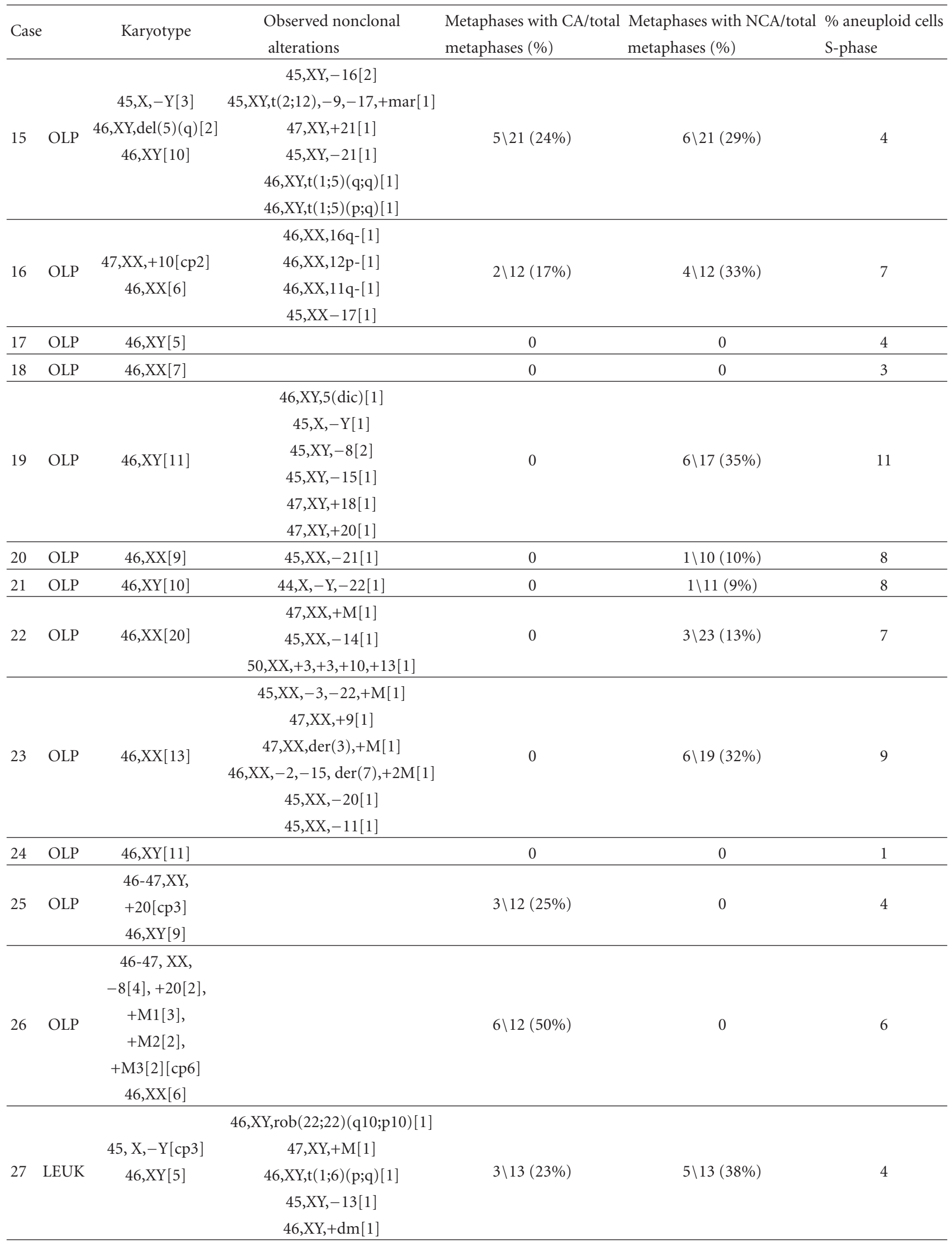


Table 1: Continued.

\begin{tabular}{lcccccc}
\hline Case & & Karyotype & $\begin{array}{c}\text { Observed nonclonal } \\
\text { alterations }\end{array}$ & $\begin{array}{c}\text { Metaphases with CA/total } \\
\text { metaphases }(\%)\end{array}$ & $\begin{array}{c}\text { Metaphases with NCA/total } \\
\text { metaphases }(\%)\end{array}$ & $\begin{array}{c}\% \text { aneuploid cells } \\
\text { S-phase }\end{array}$ \\
\hline 28 & LEUK & $46, \mathrm{XX}[4]$ & & 0 & 0 & $1 \backslash 11(9 \%)$ \\
\hline 29 & LEUK & $46, \mathrm{XX}[10]$ & $45, \mathrm{XX},-21[1]$ & 0 & 0 & 0 \\
\hline 30 & LEUK & $46, \mathrm{XY}[12]$ & & 0 & 0 & 5 \\
\hline 31 & LEUK & $46, \mathrm{XX}[20]$ & & 0 & $2 \backslash 12(17 \%)$ \\
\hline 32 & LEUK & $46, \mathrm{XX}[10]$ & & 0 & 2 \\
\hline 33 & LEUK & $46, \mathrm{XY}[10]$ & $\begin{array}{c}46, \mathrm{XY},-10,+18[1] \\
45, \mathrm{XY},-17[1]\end{array}$ & 0 & $1 \backslash 13(8 \%)$ \\
\hline
\end{tabular}

specimen by procedures studying DNA content or procedures investigating chromosomal alterations in cultured and proliferating cells. This evidence seems to indicate that changes in DNA content may reflect corresponding karyotype alterations, thereby emphasizing the importance of genetic analysis procedures that can be readily implemented in routine practice.

\section{References}

[1] C. Lengauer, K. W. Kinzler, and B. Vogelstein, "Genetic instabilities in human cancers," Nature, vol. 396, no. 6712, pp. 643-649, 1998.

[2] S. C. Reshmi, W. S. Saunders, D. M. Kudla, C. R. Ragin, and S. M. Gollin, "Chromosomal instability and marker chromosome evolution in oral squamous cell carcinoma," Genes Chromosomes and Cancer, vol. 41, no. 1, pp. 38-46, 2004.

[3] C. Jin, Y. Jin, J. Wennerberg, K. Annertz, J. Enoksson, and F. Mertens, "Cytogenetic abnormalities in 106 oral squamous cell carcinomas," Cancer Genetics and Cytogenetics, vol. 164, no. 1, pp. 44-53, 2006.

[4] S. K. Mithani, W. K. Mydlarz, F. L. Grumbine, I. M. Smith, and J. A. Califano, "Molecular genetics of premalignant oral lesions," Oral Diseases, vol. 13, no. 2, pp. 126-133, 2007.

[5] J. Brieger, R. Jacob, H. S. Riazimand, et al., "Chromosomal aberrations in premalignant and malignant squamous epithelium," Cancer Genetics and Cytogenetics, vol. 144, no. 2, pp. 148-155, 2003.

[6] P. K. Ha, N. E. Benoit, R. Yochem, et al., "A transcriptional progression model for head and neck cancer," Clinical Cancer Research, vol. 9, no. 8, pp. 3058-3064, 2003.

[7] C. Garnis, J. Campbell, L. Zhang, M. P. Rosin, and W. L. Lam, "OCGR array: an oral cancer genomic regional array for comparative genomic hybridization analysis," Oral Oncology, vol. 40, no. 5, pp. 511-519, 2004.

[8] S. M. Lippman and W. K. Hong, "Molecular markers of the risk of oral cancer," The New England Journal of Medicine, vol. 344, no. 17, pp. 1323-1326, 2001.

[9] S. M. Gollin, "Chromosomal alterations in squamous cell carcinomas of the head and neck: window to the biology of disease," Head \& Neck, vol. 23, no. 3, pp. 238-253, 2001.

[10] K. Uchida, A. Oga, M. Okafuji, et al., "Molecular cytogenetic analysis of oral squamous cell carcinomas by comparative genomic hybridization, spectral karyotyping, and fluorescence in situ hybridization," Cancer Genetics and Cytogenetics, vol. 167, no. 2, pp. 109-116, 2006.
[11] W.-W. Jiang, H. Fujii, T. Shirai, H. Mega, and M. Takagi, "Accumulative increase of loss heterozygosity from leukoplakia to foci of early cancerization in leukoplakia of the oral cavity," Cancer, vol. 92, no. 9, pp. 2349-2356, 2001.

[12] M. P. Rosin, X. Cheng, C. Poh, et al., "Use of allelic loss to predict malignant risk for low-grade oral epithelial dysplasia," Clinical Cancer Research, vol. 6, no. 2, pp. 357-362, 2000.

[13] L. Zhang, K.-J. Cheung Jr., W. L. Lam, et al., "Increased genetic damage in oral leukoplakia from high risk sites: potential impact on staging and clinical management," Cancer, vol. 91, no. 11, pp. 2148-2155, 2001.

[14] N. Pandis, G. Bardi, and S. Heim, "Interrelationship between methodological choices and conceptual models in solid tumor cytogenetics," Cancer Genetics and Cytogenetics, vol. 76, no. 2, pp. 77-84, 1994.

[15] A. Högmo, E. Munck-Wikland, R. Kuylenstierna, J. Lindholm, and G. Auer, "Nuclear DNA content and p53 immunostaining in metachronous preneoplastic lesions and subsequent carcinomas of the oral cavity," Head \& Neck, vol. 18, no. 5, pp. 433440, 1996.

[16] T. W. Remmerbach, H. Weidenbach, A. Hemprich, and A. Böcking, "Earliest detection of oral cancer using non-invasive brush biopsy including DNA-image-cytometry: report on four cases," Analytical Cellular Pathology, vol. 25, no. 4, pp. 159166, 2003.

[17] D. Maraki, J. Becker, and A. Boecking, "Cytologic and DNAcytometric very early diagnosis of oral cancer," Journal of Oral Pathology and Medicine, vol. 33, no. 7, pp. 398-404, 2004.

[18] A. Adeyinka, B. Baldetorp, F. Mertens, et al., "Comparative cytogenetic and DNA flow cytometric analysis of 242 primary breast carcinomas," Cancer Genetics and Cytogenetics, vol. 147, no. 1, pp. 62-67, 2003.

[19] Y. Hashimoto, A. Oga, K. Okami, Y. Imate, Y. Yamashita, and K. Sasaki, "Relationship between cytogenetic aberrations by CGH coupled with tissue microdissection and DNA ploidy by laser scanning cytometry in head and neck squamous cell carcinoma," Cytometry Part A, vol. 40, no. 2, pp. 161-166, 2000.

[20] A. K. El-Naggar, M. Dinh, S. L. Tucker, D. Swanson, K. Steck, and P. Vielh, "Numerical chromosomal changes in DNA hypodiploid solid tumors: restricted loss and gain of certain chromosomes," Cytometry Part A, vol. 37, no. 2, pp. 107-112, 1999.

[21] M. Okafuji, M. Ita, A. Oga, et al., "The relationship of genetic aberrations detected by comparative genomic hybridization to DNA ploidy and tumor size in human oral squamous cell carcinomas," Journal of Oral Pathology and Medicine, vol. 29, no. 5, pp. 226-231, 2000. 
[22] J. Hemmer and W. Prinz, "Comparison of DNA flow cytometry and fluorescence in situ hybridization with a set of 10 chromosome-specific DNA probes in four head and neck carcinomas," Cancer Genetics and Cytogenetics, vol. 97, no. 1, pp. 35-38, 1997.

[23] A. K. El Naggar and P. A. Reichart, "Proliferative verrucous leukoplakia and precancerous conditions," in Pathology and Genetics Head and Neck Tumors, L. Barnes, J. W. Eveson, P. Reichart, and D. Sidranski, Eds., World Health Organization Classification of Tumours, pp. 180-181, IARC Press, Lyon, France, 2005.

[24] N. Gale, B. Z. Pilch, D. Sidransky, et al., "Epithelial precursor lesions," in Pathology and Genetics Head and Neck Tumours, L. Barnes, J. W. Eveson, P. Reichart, and D. Sidranski, Eds., World Health Organization Classification of Tumours, pp. 177-179, IARC Press, Lyon, France, 2005.

[25] E. H. van der Meij and I. van der Waal, "Lack of clinicopathologic correlation in the diagnosis of oral lichen planus based on the presently available diagnostic criteria and suggestions for modifications," Journal of Oral Pathology \& Medicine, vol. 32, no. 9, pp. 507-512, 2003.

[26] S. Heim and F. Mitelman, "Cytogenetic methods and terminology," in Cancer Cytogenetics, S. Heim and F. Mitelman, Eds., chapter 2, pp. 8-9, John Wiley \& Sons, New York, NY, USA, 2nd edition, 1995.

[27] N. A. Bérgamo, L. C. da Silva Veiga, P. P. dos Reis, et al., "Classic and molecular cytogenetic analysis reveal chromosomal gains and losses correlated with survival in head and neck cancer patients," Clinical Cancer Research, vol. 11, no. 2, pp. 621-631, 2005.

[28] R. J. C. Slebos, E. Livanos, H.-W. Yim, et al., "Chromosomal abnormalities in bronchial epithelium from smokers, nonsmokers, and lung cancer patients," Cancer Genetics and Cytogenetics, vol. 159, no. 2, pp. 137-142, 2005.

[29] F. Mitelman, Ed., ISCN 1995: An International System for Human Cytogenetic Nomenclature, S. Karger, Basel, Switzerland, 1995.

[30] G. Haroske, J. P. A. Baak, H. Danielsen, et al., "Fourth updated ESACP consensus report on diagnostic DNA image cytometry," Analytical Cellular Pathology, vol. 23, no. 2, pp. 8995, 2001.

[31] J. A. Akervall, Y. Jin, J. P. Wennerberg, et al., "Chromosomal abnormalities involving $11 \mathrm{q} 13$ are associated with poor prognosis in patients with squamous cell carcinoma of the head and neck," Cancer, vol. 76, no. 5, pp. 853-859, 1995.

[32] C. Jin, Y. Jin, J. Wennerberg, et al., "Clonal chromosome aberrations accumulate with age in upper aerodigestive tract mucosa," Mutation Research/Fundamental and Molecular Mechanisms of Mutagenesis, vol. 374, no. 1, pp. 63-72, 1997.

[33] W. S. Saunders, M. Shuster, X. Huang, et al., "Chromosomal instability and cytoskeletal defects in oral cancer cells," Proceedings of the National Academy of Sciences of the United States of America, vol. 97, no. 1, pp. 303-308, 2000.

[34] F. Mitelman, Catalog of Chromosome Aberrations in Cancer, John Wiley \& Sons, New York, NY, USA, 5th edition, 1994.

[35] F. Mitelman, B. Johansson, N. Mandahl, and F. Mertens, "Clinical significance of cytogenetic findings in solid tumors," Cancer Genetics and Cytogenetics, vol. 95, no. 1, pp. 1-8, 1997.

[36] L. Montebugnoli, A. Farnedi, C. Marchetti, E. Magrini, A. Pession, and M. P. Foschini, "High proliferative activity and chromosomal instability in oral lichen planus," International Journal of Oral and Maxillofacial Surgery, vol. 35, no. 12, pp. 1140-1144, 2006.
[37] D. Maraki, S. Yalcinkaya, N. Pomjanski, M. Megahed, A. Boecking, and J. Becker, "Cytologic and DNA-cytometric examination of oral lesions in lichen planus," Journal of Oral Pathology and Medicine, vol. 35, no. 4, pp. 227-232, 2006.

[38] Z. Pektaş, A. Keskin, Ö. Günhan, and Y. Karslioğlu, "Evaluation of nuclear morphometry and DNA ploidy status for detection of malignant and premalignant oral lesions: quantitative cytologic assessment and review of methods for cytomorphometric measurements," Journal of Oral and Maxillofacial Surgery, vol. 64, no. 4, pp. 628-635, 2006.

[39] C. Scully, J. Sudbø, and P. M. Speight, "Progress in determining the malignant potential of oral lesions," Journal of Oral Pathology and Medicine, vol. 32, no. 5, pp. 251-256, 2003.

[40] M. Steinarsdóttir, J. G. Jónasson, I. Pétursdóttir, H. Sigurdsson, and H. M. Ögmundsdóttir, "A comparison of cytogenetic studies and flow cytometry in breast carcinomas," Cytometry Part A, vol. 28, no. 4, pp. 323-328, 1997.

[41] O. Driemel, K. Kraft, and J. Hemmer, "Flow cytometric Sphase fraction contributes to diagnosis of diploid malignant salivary gland tumours," International Journal of Oral and Maxillofacial Surgery, vol. 35, no. 10, pp. 947-950, 2006.

[42] A. Chassevent, M.-L. Jourdan, S. Romain, et al., "S-phase fraction and DNA ploidy in 633 T1T2 breast cancers: a standardized flow cytometric study," Clinical Cancer Research, vol. 7, no. 4, pp. 909-917, 2001.

[43] M.-L. Jourdan, M. Ferrero-Poüs, F. Spyratos, S. Romain, P.-M. Martin, and A. Chassevent, "Flow cytometric S-phase fraction measurement in breast carcinoma: influence of software and histogram resolution," Cytometry Part A, vol. 48, no. 2, pp. 6670, 2002.

[44] R. Oya and K. Ikemura, "Can flow cytometrically determined dna ploidy and S-phase fraction predict regional metastasis in squamous cell carcinoma of the oral cavity?" Head \& Neck, vol. 24, no. 2, pp. 136-142, 2002.

[45] B. Baldetorp, P.-O. Bendahl, M. Fernö, et al., "Reproducibility in DNA flow cytometric analysis of breast cancer: comparison of 12 laboratories' results for 67 sample homogenates," Cytometry Part B, vol. 22, no. 2, pp. 115-127, 1995.

[46] R. Silvestrini, A. Luisi, M. G. Daidone, et al., "Quality control for evaluation of the S-phase fraction by flow cytometry: a multicentric study," Cytometry Part B, vol. 18, no. 1, pp. 11$16,1994$.

[47] R. P. Wersto and M. Stetler-Stevenson, "Debris compensation of DNA histograms and its effect on S-phase analysis," Cytometry Part A, vol. 20, no. 1, pp. 43-52, 1995.

[48] D. M. Monasebian and J. D. Ruskin, "Flow cytometric analysis of squamous cell carcinoma of the tongue," Journal of Oral and Maxillofacial Surgery, vol. 52, no. 6, pp. 574-579, 1994.

[49] J. A. Squire, J. Bayani, C. Luk, et al., "Molecular cytogenetic analysis of head and neck squamous cell carcinoma: by comparative genomic hybridization, spectral karyotyping, and expression array analysis," Head \& Neck, vol. 24, no. 9, pp. 874-886, 2002.

[50] G. Lodi, C. Scully, M. Carrozzo, M. Griffiths, P. Sugerman, and K. Thongprasom, "Current controversies in oral lichen planus: report of an international consensus meeting. Part 2. Clinical management and malignant transformation," Oral Surgery, Oral Medicine, Oral Pathology, Oral Radiology and Endodontology, vol. 100, no. 2, pp. 164-178, 2005.

[51] M. D. Mignogna, S. Fedele, L. Lo Russo, L. Lo Muzio, and E. Bucci, "Immune activation and chronic inflammation as the cause of malignancy in oral lichen planus: is there any evidence?" Oral Oncology, vol. 40, no. 2, pp. 120-130, 2004. 